\title{
THE ROLE OF WOM AND THE COMPETENCY OF PARAMEDICAL COMMUNICATIONS TOWARD THE DECISION TO ADOPTING TRUST-MEDIATED TELEMEDICINE IN PANDEMIC TIMES COVID-19
}

\author{
Ida Bagus Udayana Putra*, Dewa Ayu Widari \\ University of Warmadewa, Denpasar, Bali, Indonesia \\ *E-mail: udayanap10@gmail.com
}

\begin{abstract}
The purpose of this study is to examine aspects of word of mouth and paramedic communication competence and trust such as that's influence patient to decide using telemedicine, as we know telemedicine is the alternative for a patient who will be able to receive health services during the Covid-19 pandemic. The number of respondents in this study was 85 respondents. The respondents were people in the city of Denpasar. Data from the questionnaires were then analyzed using SEM-PLS. Based on the results, several conclusions are obtained namely (1) Word of Mouth has a positive but insignificant effect on the decision to adopt telemedicine. (2) Paramedic Communication Competence has a positive and significant effect on the decision to adopt telemedicine. (3) Word of Mouth has a positive and significant effect on Trust in adopting telemedicine. (4) Paramedic communication competence has a positive and significant effect on Trust in adopting telemedicine. (5). Trust is a mediating variable that relates the Word Of Mouth variable and Paramedic Communication Competence to the decision to adopt telemedicine.
\end{abstract}

\section{KEY WORDS}

WOM, paramedic communication competence, trust, telemedicine, SEM-PLS.

The global pandemic caused by severe acute respiratory syndrome COVID-19 is an infectious disease caused by acute respiratory syndrome coronavirus 2 (Severe acute respiratory syndrome coronavirus 2 or SARSCoV-2). Positive cases in Bali amounted to 12,759 so that until now Bali ranks the tenth largest in Indonesia (Darma \& Saputra, 2021; Sara et al., 2020). There is a concern that the suspension of services has a negative health impact, so that the use of telemedicine can provide a viable alternative to be considered by the Circular of the Minister of Health Number HK.02. / MENKES/303/2020 Year 2020 Regarding the provision of remote health services by health professionals using information and communication technology, where services include the exchange of information on diagnosis, treatment, prevention of disease and injury, research and evaluation, and continuing education of health service providers for the benefit of improving individual and community health, there are still few who use health applications, about $10 \%$ of the population in Indonesia and not all areas in Indonesia are affordable and have good internet quality(Mahmud \& Riley, 2021; Uğur \& Akbıyık, 2020).

Meanwhile, during the pandemic, $10 \%$ is considered small, because it is expected that around $20-30 \%$ of users will increase so that patients who have mild illnesses and can be treated with telemedicine can choose telemedicine as their main choice in choosing health services(Darma \& Saputra, 2021; Uğur \& Akbıyık, 2020). About $10 \%$ of the total population in Indonesia and not all areas in Indonesia are affordable and have good internet quality. Meanwhile, during the pandemic, $10 \%$ is considered small, because it is expected that around $20-30 \%$ of users will increase so that patients who have mild illnesses and can be treated with telemedicine can choose telemedicine as their main choice in choosing health services. About $10 \%$ of the total population in Indonesia and not all areas in Indonesia are affordable and have good internet quality. Meanwhile, during the pandemic, $10 \%$ is considered small, because it is expected that around $20-30 \%$ of users will increase so that patients who have mild illnesses and can be treated with telemedicine can choose telemedicine as their main choice in choosing health services. (Huang et al., 2011) also 
stated that WOM has a significant influence on patients' decisions to choose the health service decisions they use. Several studies have explored which physician attributes influence patients' cognitive and affective trust in physicians, and how these two variables and their relationship affect patients' willingness to adopt telemedicine studies. Fergusson et al. (2006) stated that the doctor's attributes in conveying information had a significant influence on the patient's cognitive trust so that it influenced the patient's decision to use online health. A study conducted by Deloitte Indonesia, Bahar Law Firm and Indonesian Chapters (August 2019) A total of $61.2 \%$ chose not to use health applications due to lack of trust, several journals support a significant relationship as found Dugdale et al. (1999) building patient-physician trust is important in developing and improving rural health in addition to being supported Roter et al. (1988) also said that there was a significant positive effect between patient trust in health care providers on patients' decisions to use on-line health services in this case the same as telemedicine. Therefore, using telemedicine in providing health services to the community (Bashshur, 1995).

Telemedicine is an innovative approach to managing the COVID-19 situation. Despite the unavoidable pandemic, there is an opportunity to prepare the infrastructure to provide treatment using Telemedicine (Perednia \& Allen, 1995). So that in the future once the current pandemic has ended, Telemedicine can continue to be used to provide more comfortable treatment to patients. The current COVID-19 pandemic is forcing many health systems to proactively reduce the provision of health services to reduce contact with health care facilities in order to avoid exposure to the virus. There is concern that suspension of services has negative health impacts, so the use of telemedicine may provide a viable alternative to consider (Wootton, 1996). Public information in particular plays an important role in the implementation of adherence to public health guidelines and fact-based communication with peers and patient (Grigsby \& Sanders, 1998). Although the majority of health care providers rate the quality and quantity of communication positively, there are concerns that the suspension of services has negative health impacts, so the use of telemedicine may provide a viable alternative to consider. Public information in particular plays an important role in the implementation of adherence to public health guidelines and fact-based communication with peers and patients (Heinzelmann et al., 2005). Although the majority of health care providers rate the quality and quantity of communication positively, there are concerns that the suspension of services has negative health impacts, so the use of telemedicine may provide a viable alternative to consider (Yellowless, 2005). Public information in particular plays an important role in the implementation of adherence to public health guidelines and fact-based communication with peers and patients. Although the majority of healthcare providers rate the quality and quantity of communication positively.

\section{LITERATURE REVIEW}

Telemedical, derived from the word "tele-" which means "distance far away", and "medical" which means "character medicine". Telemedicine is the use of telecommunications to provide long-distance medical information and services. Doctors need to be aware that telemedicine vehicles have limitations in providing complete information on the patient's clinical condition (Heinzelmann et al., 2005). Doctors must consider whether the information on the patient's clinical condition that is presented is not complete enough to generate adequate professional confidence so that it can then be followed up to make a diagnosis and determine treatment for the patient (Yellowless, 2005). This limited information has the potential to cause medical services to be completely limited or even make wrong decisions. Doctors and telemedical services need to be registered centrally (Field, 1996).

Word of mouth can build customer trust. While according to Kitapci et al. (2014) Word of mouth is a conversation that naturally occurs between people. Word of mouth is genuine consumer talk. Lu and Wu (2016) define word of mouth as a personal communication about the buyer's product and the people around him. Word of Mouth (WOM) is word of mouth communication that arises when people receive services. 
Telemedicine or have heard of information about telemedicine, besides that it is a part of Social Information that influences the decision to purchase or use services, be it commercial or health services. Study from Liu et al. (2019) found that information spread by word of mouth had a statistically significant effect on the intensity of online purchases. This happens because the mindset formed by an individual about certain products or services is informal and can influence the decisions of other individuals (Ardani et al., 2012).

Effective paramedic communication competence by a team of doctors who will later practice telemedicine. Study from Ross et al. (2014) found that the message is the most basic element in communication if the message delivered by the communicator can change the knowledge, attitude, and behavior of the communicant. To achieve these goals, it is necessary to have a communication strategy, communication message planning and communicator ethos, this statement is supported by Boyle et al. (2011) building patient trust in doctors is important. Well-developed physician communication skills contribute to the implementation of patient decisions in deciding which health services to use.

News delivered by WOM, especially those that have a significant positive effect on the trust of a person or consumer to use or decide to use an object or service. In his Devaney (2016) The results have proven that trust predicts the adoption of information in word of mouth which advances the e-WOM literature as previous studies found that information usefulness and credibility both predict information adoption. Trust is an expectation held by an individual or a group when words, promises, verbal or written statements from an individual or other group can be realized. the need for trust by the patient that arises from the concerns of the patient, so that patient data is confidential and confidential, in which there is text, audio, and video, is sensitive data and needs to be kept from being published. This is where the function of a doctor or paramedic is responsible. to provide maximum medical care and protection. Several journals support a significant relationship as found by $\mathrm{Lu}$ and $\mathrm{Wu}$ (2016). Paramedic communication competence is said to have an influence on the patient's trust or trust.

The trust will strengthen the information provided by WOM is said by a study from the perspective of the community (Saputra et al., 2020), the obstacles to the equitable provision of Telemedicine and Telehealth apart from internet and information technology equipment constraints, but also in terms of digital literacy, the language used in health applications, and trust in online system security (Kassim et al., 2012; Porter et al., 2011). Some community groups do not trust the security and privacy rights of health application users. Some also doubt the certification of doctors who provide online consultations or the effectiveness of examinations with telecommunications. This misconception arises because of the lack of public knowledge about the development of Telemedicine. Research results of Heinzelmann et al. (2005)shows that the ability of doctors has a significant positive effect on the cognitive trust of patients in doctors; The doctor's integrity and virtue have a significant positive effect on the patient's affective trust in the doctor; cognitive and affective beliefs have a significant positive effect on the patient's willingness to choose and there is a significant positive interaction between affective and cognitive beliefs (Giampietri et al., 2018; Gupta et al., 2019).

\section{METHODS OF RESEARCH}

The study was conducted by collecting data through an online survey of patients and who will become patients in Denpasar City. Data collection was carried out simultaneously in one short study or cross section through a questionnaire. The scope of this research was conducted in Denpasar. The scope of the variables studied were WOM, attention, communication, trust and decisions to use telemedicine. The population in this study is people who live in Denpasar City. The sample in this study amounted to 85 samples. Data was collected using a 5-point Likert scale and collected using a questionnaire using Google form. The questionnaire has been tested for reliability and validity and distributed to 30 respondents. All indicators show the correlation coefficient value above $>0.30$ with $a$ 
significance level of 0.05 for validity, and the Cronbach alpha value above $>0.70$ so that it is declared reliable.

\section{RESULTS OF STUDY}

Characteristics of respondents in this study can be explained that there are 85 respondents and divided into several ages including $<30$ years, 30-40 years, $>40$ years. The majority of respondents were dominated by age > 40 years by $60 \%$. Gender is dominated by women (64.7\%). Male respondents were $35.3 \%$. Respondents based on education are dominated by undergraduates with a percentage of $69.5 \%$. Most of the respondents had undergraduate education as many as 59 people $(69.5 \%)$, then followed by other education as many as 17 people (20\%), Master education as many as 6 people (7\%) and the lowest was high school education as many as 3 people $(3.5 \%)$. This shows that the respondents come from highly educated circles. In connection with the indicators that make up the latent variables in this study are reflective, and then the evaluation of the measurement model (measurement model / outer model).

Table 1 - Outer model result

\begin{tabular}{|c|c|c|c|c|}
\hline & Original Sample $(\mathrm{O})$ & Sample mean (M) & Standard Deviation (STDEV) & T Statistics (| O/STERR $\mid$ ) \\
\hline $\mathrm{X} 1.1<-$ WOM & 0.923 & 0.922 & 0.019 & 48.028 \\
\hline $\mathrm{X} 1.2<-$ WOM & 0.820 & 0.821 & 0.051 & 16,228 \\
\hline $\mathrm{X} 1.3<-$ WOM & 0.855 & 0.855 & 0.031 & 27,299 \\
\hline $\mathrm{X} 1.4<-$ WOM & 0.840 & 0.844 & 0.034 & 24,489 \\
\hline X2.1 <- Communication Competence Paramedic & 0.876 & 0.877 & 0.026 & 33,695 \\
\hline X2.2 <- Communication Competence Paramedic & 0.855 & 0.855 & 0.036 & 24,021 \\
\hline X2.3 <- Communication Competence Paramedic & 0.826 & 0.830 & 0.039 & 21,020 \\
\hline X2.4 <- Communication Competence Paramedic & 0.797 & 0.797 & 0.060 & 13,235 \\
\hline X2.5 <- Communication Competence Paramedic & 0.878 & 0.880 & 0.034 & 25,986 \\
\hline X2.6 <- Communication Competence Paramedic & 0.863 & 0.864 & 0.036 & 23,857 \\
\hline Z1.1<-Trust & 0.879 & 0.878 & 0.044 & 20.037 \\
\hline Z1.2<-Trust & 0.882 & 0.881 & 0.056 & 15,665 \\
\hline Z1.3<-Trust & 0.873 & 0.866 & 0.047 & 18,444 \\
\hline Z1.4<-Trust & 0.820 & 0.826 & 0.041 & 20,181 \\
\hline Y1.1 <- Adoption Decision Telemedicine & 0.895 & 0.897 & 0.023 & 38,168 \\
\hline Y1.2 <- Adoption Decision Telemedicine & 0.866 & 0.864 & 0.034 & 25,333 \\
\hline Y1.3 <- Adoption Decision Telemedicine & 0.856 & 0.859 & 0.035 & 24,352 \\
\hline
\end{tabular}

The results of the calculation of the outer loading value show that all indicators have met the valid requirements based on the discriminant validity criteria, namely the outer loading value $>0.50$ and is statistically significant.

Table 2 - Discriminant validity results

\begin{tabular}{lllll}
\hline & Word Of Mouth & Communication Competence Paramedic & Trust & Decision to adopt Telemedicine \\
\hline $\mathrm{X} 1.1$ & 0.923 & 0.637 & 0.709 & 0.554 \\
\hline $\mathrm{X} 1.2$ & 0.820 & 0.512 & 0.619 & 0.486 \\
\hline $\mathrm{X} 1.3$ & 0.855 & 0.666 & 0.738 & 0.608 \\
\hline $\mathrm{X} 1.4$ & 0.840 & 0.677 & 0.693 & 0.550 \\
\hline $\mathrm{X} 2.1$ & 0.730 & 0.876 & 0.757 & 0.724 \\
\hline $\mathrm{X} 2.2$ & 0.641 & 0.855 & 0.666 & 0.634 \\
\hline $\mathrm{X} 2.3$ & 0.586 & 0.826 & 0.653 & 0.714 \\
\hline $\mathrm{X} 2.4$ & 0.540 & 0.797 & 0.640 & 0.510 \\
\hline $\mathrm{X} 2.5$ & 0.619 & 0.878 & 0.722 & 0.585 \\
\hline $\mathrm{X} 2.6$ & 0.582 & 0.863 & 0.692 & 0.657 \\
\hline $\mathrm{Z} 1.1$ & 0.600 & 0.739 & 0.684 & 0.879 \\
\hline $\mathrm{Z} 1.2$ & 0.526 & 0.601 & 0.646 & 0.882 \\
\hline $\mathrm{Z} 1.3$ & 0.560 & 0.639 & 0.624 & 0.873 \\
\hline $\mathrm{Z} 1.4$ & 0.674 & 0.647 & 0.820 & 0.552 \\
\hline $\mathrm{Y} 1.1$ & 0.813 & 0.685 & 0.895 & 0.692 \\
\hline $\mathrm{Y} 1.2$ & 0.667 & 0.765 & 0.866 & 0.643 \\
\hline $\mathrm{Y} 1.3$ & 0.606 & 0.694 & 0.856 & 0.661 \\
\hline
\end{tabular}

Table 2.shows that the cross loading index value of all indicators in each construct is generally greater than the index value of other indicators on other constructs in one block, so it is declared valid based on discriminant validity criteria. 
Table 3 - Results of composite reliability and Cronbach's Alpha

\begin{tabular}{llcl}
\hline & \multicolumn{1}{c}{ Cronbach's Alpha rho_AComposite Reliability } & AVerage Variance Extracted (AVE) \\
\hline Word Of Mouth (WOM) & 0.882 & 0.8860 .919 & 0.740 \\
\hline Communication Competence Paramedic & 0.923 & 0.9260 .940 & 0.722 \\
\hline Trust & 0.882 & 0.8860 .919 & 0.739 \\
\hline
\end{tabular}

Table 3 shows that the composite reliability value of each construct is greater than 0.70 , as well as the Cronbach's Alpha value of all constructs has an index value greater than 0.70 . This means that it meets the reliable requirements based on the composite reliability criteria.

Table 4 - Results of goodness of fit Model

\begin{tabular}{lcc}
\hline CONSTRUCT & R Square & AVE \\
\hline Adoption Decision Telemedicine & 0.620 & 0.771 \\
\hline Communication Competence Paramedic & 0.722 & \\
\hline Trust & 0.756 & 0.739 \\
\hline WOM & 0.740 & 0.688 \\
\hline AVERAGE & 0.743 & \\
\hline
\end{tabular}

In Table 4 the calculation using Gof shows the average R2 value of 0.688 while the average Communality is 0.743 , then the Gof value is $A . R 2{ }^{*} A . A V E=0.688^{*} 0.743=0.511=$ 0.715 It means that the global model is predictive large ones.

Table 5 - Live Effect Test

\begin{tabular}{ll}
\hline Paramedic Communication Competence --> Decision to Adopt Telemedicine & 0.4390 .4390 .129 3,409 Significant \\
\hline Paramedic Communication Competence -->Trust & $0.4800 .4680 .1104,372$ Significant \\
\hline Trust -->Adopting Decision Telemedicine & $0.3620 .3560 .1622,239$ Significant \\
\hline WOM--> Adoption Decision Telemedicine & 0.0310 .0510 .1700 .180 Not significant \\
\hline WOM-->Trust & $0.4550 .4710 .1143,989$ Significant \\
\hline
\end{tabular}

Based on the table above for path analysis and hypothesis testing, it is expected that $\mathrm{Ho}$ is rejected or sig value $<0.05$ (or t statistic value $>1.96$ with a significant level of 0.05 ). So that $\mathrm{H} 2, \mathrm{H} 3, \mathrm{H} 4$, and $\mathrm{H} 5$ are positive and significant so that the hypothesis is accepted, but $\mathrm{H} 1$ has an insignificant positive relationship because it has a t-statistic value of 0.180 and is smaller than the t-table value so that the hypothesis is rejected.

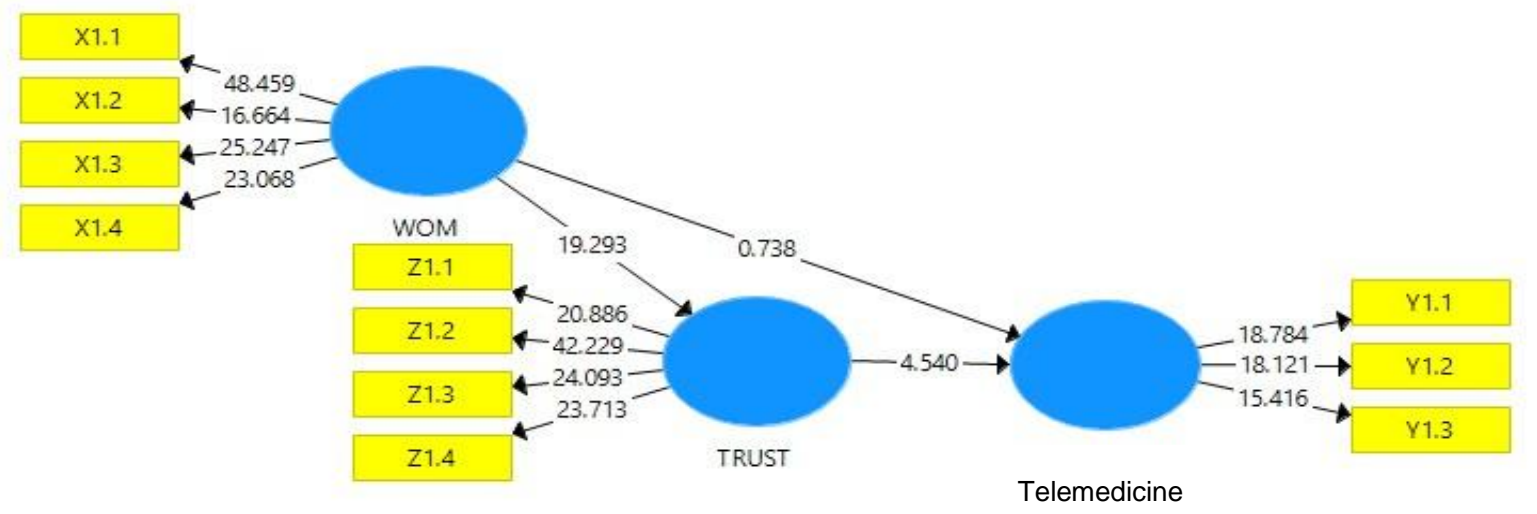

Figure 2 - Statistical Test of the Mediation Role of Trust on WOM on the Decision to Adopt Telemedicine (Indirect effect)

The effect of mediation analyzed includes the analysis of direct and indirect effects. The analysis in this study uses the examination method. Figure 2 shows the relationship between WOM and trust which is significant, which is 19.293 higher than T table 1.96, as well as Trust to the decision to adopt telemedicine at 4.540 (significant), but WOM to the decision to adopt is 0.738 which means it is not significant because the value is smaller than 
T. Table (1.96), therefore according to Martin (2017) the intervening variable, namely trust, is said to be a perfect mediation (full mediation) between WOM and the decision to adopt Telemedicine. While in Figure 3. Shows the relationship of paramedical communication competence to significant trust at 19.672 , Trust to the decision to adopt is significant at 3,171 as well as the relationship between paramedical communication competence and the decision to adopt telemedicine is significant at 3.734. The value of the competence direct relationship variable is 0.761 , which is smaller than the statistical test value of the direct relationship between paramedic communication competence and the decision to adopt telemedicine which is worth 17.705 , so that according to Martin (2017) the trust variable is said to be a partial mediation between paramedic communication competence and the decision to adopt telemedicine (Martin \& Grüb, 2020).

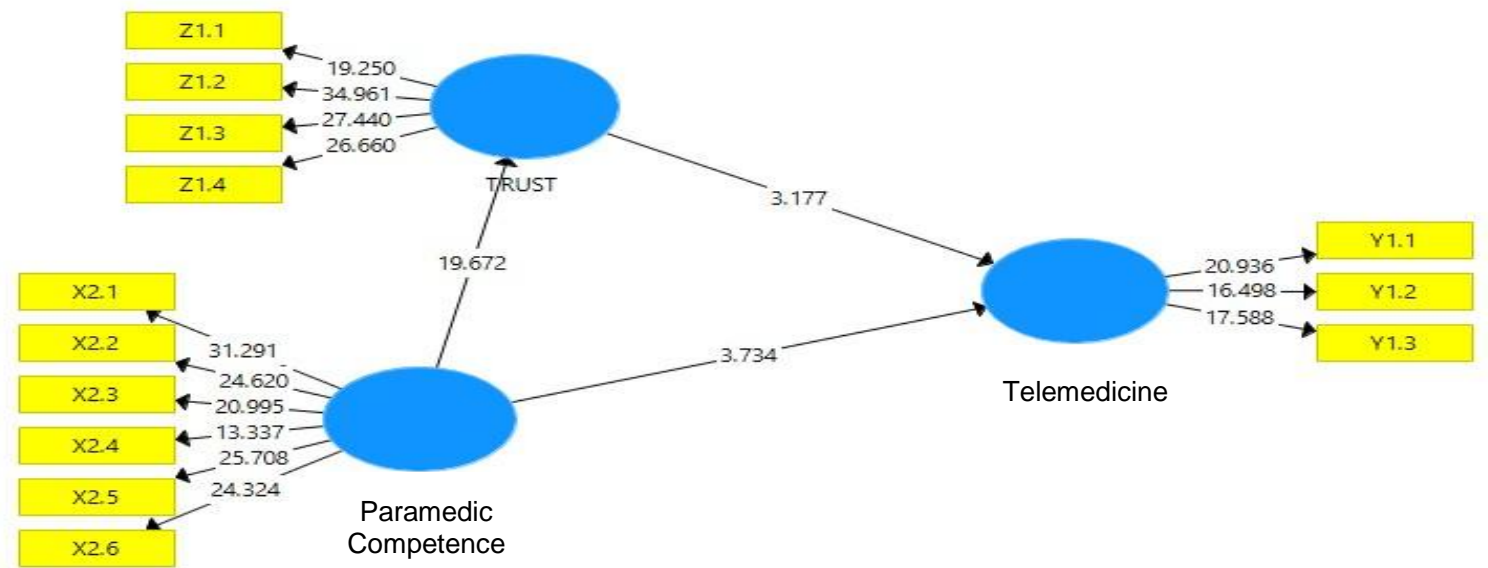

Figure 3 - Statistical Test of the Mediation Role of Trust on Paramedic Communication Competence on Decisions to Adopt Telemedicine (Indirect Effect)

\section{DISCUSSION OF RESULTS}

The Role of Word of Mouth (WOM) in the Decision to Adopt Telemedicine. The results of this test prove that $\mathrm{H} 1$ rejected. These results are supported by several studies which state that WOM has a positive but not significant effect on the decision to adopt telemedicine. research from Greiner (2017) in a recent study aligned with the pandemic, respondents' interest in adopting telemedicine was high but not significantly related to word of mouth. This contradicts the initial conclusions put forward and considering that Word Of Mouth is also a more powerful tool in the 21st century in terms of marketing. According to Kitagawa et al (2000) in the absence of a formal telehealth strategy, it is important to provide telehealth guidelines to assist in the coordination and delivery of telehealth services during an emergency. This information needs to be tailored to all stakeholders, including patients, physicians, health care providers, and funders (Huang et al., 2020).

The Role of Paramedic Communication Competence on the Decision to Adopt Telemedicine. The test results prove that $\mathrm{H} 2$ accepted. Paramedic communication competence has a positive and significant effect on the decision to adopt Telemedicine. The results of this study are in accordance with the theory which conveys that communication competence must be possessed by a doctor in implementing Telemedicine in achieving effective communication, hereinafter referred to as resources owned by a communicator to be used in the communication process (Ross et al., 2014).

WOM's Role in Trust in the decision to adopt Telemedicine. Statistical results show that Word of Mouth (WOM) has a positive effect on trust, and the relationship is significant so that H3 is accepted. This is bolstered by the theory Kitapci et al. (2014) prove that trust predicts information adoption in WOM, supported by Lu and Wu (2016) stated a significant effect between WOM and trust in influencing patients to use Telemedicine. More results by Liu et al. (2019) stated that cognitive beliefs influence the patient's decision to use Telemedicine. 
The Influence of Paramedic Communication Competence on Trust with the patient's decision to adopt telemedicine. The statistical results in this study show that paramedic communication competence has a positive effect on trust, and the relationship is significant. The results of this study are supported by previous studies regarding the relationship of communication from the medical team and doctors to the patient's decision to use Telemedicine; this contributes to the implementation of services and to build trust between doctors and patients that develops well through communication (Boyle et al., 2011). Communication made by the medical team in person is also expected to be the same as communication made online (Yellowless, 2005).

The role of Trust in mediating WOM and Paramedic Communication Competence towards the decision to adopt Telemedicine. The results of this study indicate that Trust has a role in mediating WOM and paramedic communication competence on the decision to adopt Telemedicine so that it can increase the link between WOM and communication competence with the decision to adopt Telemedicine, this study is in line with Johnson et al (2005) found that affective trust contributes significantly to customers, willingness to meet with service providers in the future. Cognitive trust and affective trust have significant value as mediation in the patient's decision to choose. Liu et al. (2019) using trust as a mediation in their research and getting informal results has significant results in choosing decision factors, so it is also mentioned in this study that trust perfectly mediates between WOM and patient decisions in using Telemedicine, but has partial mediation in terms of paramedic communication competence with decision to adopt Telemedicine (Borodin et al., 2020).

\section{CONCLUSION}

Based on the results obtained, the conclusions obtained are; (1) Word of Mouth has a positive but not significant effect on the decision to adopt telemedicine. (2) Paramedic Communication Competence has a positive and significant effect on the decision to adopt telemedicine. (3) Word of Mouth has a positive and significant effect on Trust adopting telemedicine. (4) Paramedic communication competence has a positive and significant effect on Trust adopting telemedicine. (5). Trust is a mediating variable that relates the Word of Mouth and Paramedic Communication Competencies to the decision to adopt telemedicine.

The important theoretical implication of this research is that it can be used as a medium for the development of knowledge related to the world of telemedicine which should be the latest research, especially in the era of the industrial revolution 4.0. The application of the Telemedicine system needs to use widely appropriate technology, so that Telemedicine can be accepted as a full alternative during the Covid-19 Pandemic. The findings of the research can help to identify the most important aspects and which need to be developed thereby changing health care providers and implementing effective marketing strategies to increase the adoption of these innovative services by patients or prospective patients, so as to provide information and policy guidelines to succeed implementing Telemedicine health services in the city of Denpasar.

\section{REFERENCES}

1. Ardani, W., Suprapti, N. W. S., \&Wayan, N. (2012). Pengaruh Kualitas Layanan Terhadap Kepuasan Dan WOM (Studi di RSUD wangaya Denpasar). E-Jurnal Manajemen Universitas Udayana, 1(2), 240-254.

2. Bashshur, R. L. (1995). On the definition and evaluation of telemedicine. Telemedicine Journal, 1(1), 19-30.

3. Borodin, R. A., Vorobiev, A. I., Evelson, L. I., Zingerman, B. V., Kremenetskaya, O. S., \&Shklovskiy-Kordy, N. E. (2020). Telemedicine System with Elements of Artificial Intelligence. In KII-2020 (pp. 95-104).

4. Boyle, M., Williams, B., Brown, T., Molly, A., McKenna, L., Palermo, C., \& Molloy, L. (2011). Listening and communication styles of undergraduate paramedic students. Journal of Paramedic Practice, 3(9), 504-509. 
5. Darma, I. K., \& Saputra, K. A. K. (2021). Analysis Of The Potential Of Motor Vehicle Taxes And The Level Of Risk During The Covid-19 Pandemic To Increase Regional Income In Bali Province. Palarch's Journal of Archaeology of Egypt/Egyptology, 18(7), 872-882.

6. Devaney, L. (2016). Good governance? Perceptions of accountability, transparency and effectiveness in Irish food risk governance. Food Policy, 62, 1-10. https://doi.org/10.1016/j.foodpol.2016.04.003

7. Dugdale, D. C., Epstein, R., \&Pantilat, S. Z. (1999). Time and the patient-physician relationship. Journal of general internal medicine, 14(Suppl 1), S34.

8. Ferguson, R. J., Paulin, M., \&Leiriao, E. (2006). Loyalty and positive word-of-mouth: patients and hospital personnel as advocates of a customer-centric health care organization. Health marketing quarterly, 23(3), 59-77.

9. Field, M. J. (Ed.). (1996). Telemedicine: A guide to assessing telecommunications for health care.

10. Giampietri, E., Verneau, F., Del Giudice, T., Carfora, V., \& Finco, A. (2018). A Theory of Planned behaviour perspective for investigating the role of trust in consumer purchasing decision related to short food supply chains. Food Quality and Preference, 64. https://doi.org/10.1016/j.foodqual.2017.09.012

11. Greiner, A. L. (2017). Telemedicine applications in obstetrics and gynecology. Clinical obstetrics and gynecology, 60(4), 853-866.

12. Grigsby, J., \& Sanders, J. H. (1998). Telemedicine: where it is and where it's going. Annals of internal medicine, 129(2), 123-127.

13. Gupta, A., Dash, S., \& Mishra, A. (2019). All that glitters is not green: Creating trustworthy ecofriendly services at green hotels. Tourism Management, 70(July 2017), 155-169. https://doi.org/10.1016/j.tourman.2018.08.015

14. Heinzelmann, P. J., Lugn, N. E., \& Kvedar, J. C. (2005). Telemedicine in the future. Journal of telemedicine and telecare, 11(8), 384-390.

15. Huang, M., Cai, F., Tsang, A. S., \& Zhou, N. (2011). Making your online voice loud: the critical role of WOM information. European Journal of Marketing.

16. Huang, Z., Wu, S., Yu, T., \& Hu, A. (2020). Efficacy of telemedicine for urinary incontinence in women: a systematic review and meta-analysis of randomized controlled trials. International Urogynecology Journal, 31, 1507-1513.

17. Kassim, E. S., Jailani, S. F. A. K., Hairuddin, H., \& Zamzuri, N. H. (2012). Information System Acceptance and User Satisfaction: The Mediating Role of Trust. Procedia Social and Behavioral Sciences, 57, 412-418. https://doi.org/10.1016/j.sbspro.2012.09.1205.

18. Kitagawa, M., Akiyama, Y., Omi, H., Sago, H., \& Natori, M. (2000). Development and clinical application of a telemedicine support system in the field of perinatal patient management. Journal of Obstetrics and Gynaecology Research, 26(6), 427-434.

19. Kitapci, O., Akdogan, C., \&Dortyol, İ. T. (2014). The impact of service quality dimensions on patient satisfaction, repurchase intentions and word-of-mouth communication in the public healthcare industry. Procedia-Social and Behavioral Sciences, 148, 161-169.

20. Liu, Y., Zhang, X., Sun, J., Jiang, Y., \& Tian, Z. (2019).Understanding Patients' WOM of IT-Enabled Healthcare Service: A Case Study of Online Health Consultation.

21. Lu, N., \& Wu, H. (2016). Exploring the impact of word-of-mouth about Physicians' service quality on patient choice based on online health communities. BMC Medical Informatics and Decision Making, 16(1), 1-10.

22. Mahmud, M., \& Riley, E. (2021). Household response to an extreme shock: Evidence on the immediate impact of the Covid-19 lockdown on economic outcomes and well-being in rural Uganda. World Development, 140(March 2020), 105318. https://doi.org/10.1016/j.worlddev.2020.105318.

23. Martin, S. (2017). Word-of-mouth in the health care sector: a literature analysis of the current state of research and future perspectives. International Review on Public and Nonprofit Marketing, 14(1), 35-56. 
24. Martin, S., \&Grüb, B. (2020).Intensive WOM-behavior in the healthcare sector-the case of an Austrian hospital's Facebook site. International Review on Public and Nonprofit Marketing, 17, 331-352.

25. Perednia, D. A., \& Allen, A. (1995). Telemedicine technology and clinical applications. Jama, 273(6), 483-488.

26. Porter, D., Andrews, M., Turkewitz, J. A., \& Wescott, C. G. (2011). Managing Public Finance and Procurement in Fragile and Conflicted Settings. International Public Management Journal, 14(4), 369-394. https://doi.org/10.1080/10967494.2011.656049

27. Roter, D. L., Hall, J. A., \& Katz, N. R. (1988). Patient-physician communication: a descriptive summary of the literature. Patient Education and Counseling, 12(2), 99-119.

28. Ross, L., Boyle, M., Williams, B., Fielder, C., \& Veenstra, R. (2014). Perceptions of student paramedic interpersonal communication competence: A cross-sectional study. Australasian journal of paramedicine, 11(4).

29. Saputra, K. A. K., Subroto, B., Rahman, A. F., \& Saraswati, E. (2020).Issues of morality and whistleblowing in short prevention accounting. International Journal of Innovation, Creativity and Change, 12(3), 77-88.

30. Sara, I. M., Saputra, K. A. K., \& Jayawarsa, A. A. K. (2020). Regulatory Impact Assessment Analysis In Traditional Village Regulations As Strengthening Culture In Bali. International Journal of Environmental, Sustainability, and Social Sciences, 1(3), 16-23.

31. Uğur, N. G., \& Akbıyık, A. (2020). Impacts of COVID-19 on global tourism industry: A cross-regional comparison. Tourism Management Perspectives, 36(September), 100744. https://doi.org/10.1016/j.tmp.2020.100744.

32. Wootton, R. (1996). Telemedicine: a cautious welcome. BMJ, 313(7069), 1375-1377.

33. Yellowlees, P. M. (2005). Successfully developing a telemedicine system. Journal of telemedicine and telecare, 11(7), 331. 